Original Research Paper

\title{
Pelatihan Pembuatan Media Pembelajaran Rumah Konversi Energi dan Penerapannya dengan Model STEM
}

\author{
Susilawati $^{1}$, Aris Doyan ${ }^{1}$ \\ ${ }^{\text {I}}$ Program Studi Pendidikan Fisika, Fakultas Keguruan dan Ilmu Pendidikan, Universitas Mataram, Indonesia
}

DOI: https://doi.org/10.29303/jpmpi.v3i2.507

Sitasi : Susilawati., \& Doyan, A. (2020). Pelatihan Pembuatan Media Pembelajaran Rumah Konversi Energi dan Penerapannya dengan Model STEM. Jurnal Pengabdian Magister Pendidikan IPA, 3(2)

\author{
Article history \\ Received: 7 July 2018 \\ Revised: 28 August 2018 \\ Accepted: 2 November 2018 \\ *Corresponding Author: \\ Susilawati, \\ Program Studi \\ Pendidikan Fisika, Fakultas \\ Keguruan dan Ilmu Pendidikan, \\ Universitas Mataram, \\ Indonesia. \\ Email: \\ susilawatihambali@unram.ac.id
}

\begin{abstract}
Kegiatan pengabdian pada masyarakat ini bertujuan untuk meningkatkan kemampuan guru dalam mendesain dan menggunakan media pembelajaran rumah konversi energi yang dierapkan dengan model STEM (Science, Technology, Engineering and Mathematics). Kegiatan ini dilakukan melalui tiga tahap yaitu persiapan, pelaksanaan, evaluasi. Secara umum kegiatan pelatihan ini berhasil dan tepat sasaran, karena peserta pelatihan merasa mendapatkan bekal cara-cara pengembangan media pembelajaran dan termotivasi untuk menerapkannya saat pembelajaran. Selain itu, peserta pelatihan cukup puas dengan diadakan pelatihan tersebut dan berkeinginan kegiatan pelatihan tersebut berkelanjutan.
\end{abstract}

Keywords: Rumah Konversi Energi, STEM.

\section{Pendahuluan}

$\mathrm{N}_{\mathrm{ke}}^{\mathrm{ilh}}$ ilai mutu pendidikan kemampuan para

sangat didukung oleh pendidik dalam melaksanakan pembelajaran. Salah satu indikator yang dijadikan acuan tingkat keberhasilan dalam pealaksanaan pendidikan adalah perolehan hasil belajar peserta didik. Perolehan hasil belajar peserta didik secara nasional masih tergolong sangat rendah seperti yang diraih pada ujian nasional. Hasil observasi yang dilakukan di sekolah menunjukkan bahwa proses pembelajaran masih tidak diikuti secara optimal oleh beberapa peserta didik. Hal ini disebabkan oleh daya imajinasi peserta didik untuk merealisasikan sebuah konsep fisika yang meskipun bersifat abstrak. Kesulitan peserta didik dalam mengimajinasi dan menganalisa suatu fenomena fisika harus segera diatasi oleh seorang pendidik.

Salah satu cara yang harus dilakukan oleh seorang guru adalah memfasilitasi peserta didik dengan media-media pembelajaran sederhana baik berupa media riil maupun media virtual. Untuk menyiapkan media riil guru haruslah merancang media yang akan diajarkan sesuai kompetensi dasar yang akan dicapai. Media konversi energi adalah salah satu media yang akan merubah seluruh energi listrik menjadi energi gerak, energi panas, energi bunyi, energi cahaya dan perubahan energi lainnya. Pemanfaatan media pembelajaran akan lebih efektif jika media pembelajaran yang digunakan sesuai dengan karakteristik model pembelajaran. Untuk itu, media konversi ini akan didesain bersama antara guru dan para peserta didiknya sehingga terbentuklah model pembelajaran STEM (Science, Technology, Engineering and Mathematics) yang mengembangkan sains, teknologi, engineering dan matermatika (Adhelacahya et al, 2020; Stehle et al, 2019). Model pembalajaran STEM merupakan model pembelajaran yang pada intinya adalah memadukan antara sains, teknologi, engineering, dan matematik (Torlakson et al, 2014). Model STEM memfokuskan proses pembelajaran yang mengeksplorasi dua atau lebih bidang yang melibatkan peserta didik aktif dalam konteks 
pemecahan masalah dalam dunia nyata (Izzati et al, 2019).

\section{Metode}

Menanggapi permasalahan yang mengakibatkan pembelajaran IPA di kelas kurang interaktif, maka permasalahan ini dapat diselesaikan dengan cara memberikan pelatihan kepada guru dalam mendesain dan menggunakan media pembelajaran rumah konversi energi. Beberapa tahapan yang akan dilalui dalam penyelesaian masalah ini yaitu tahap persiapan, tahap pelaksanaan, dan tahap evaluasi (Doyan et al, 2019; Susilawati et al, 2019). Secara sederhana tahapan pelatihan ini direpresentasikan dalam Gambar 1 berikut.

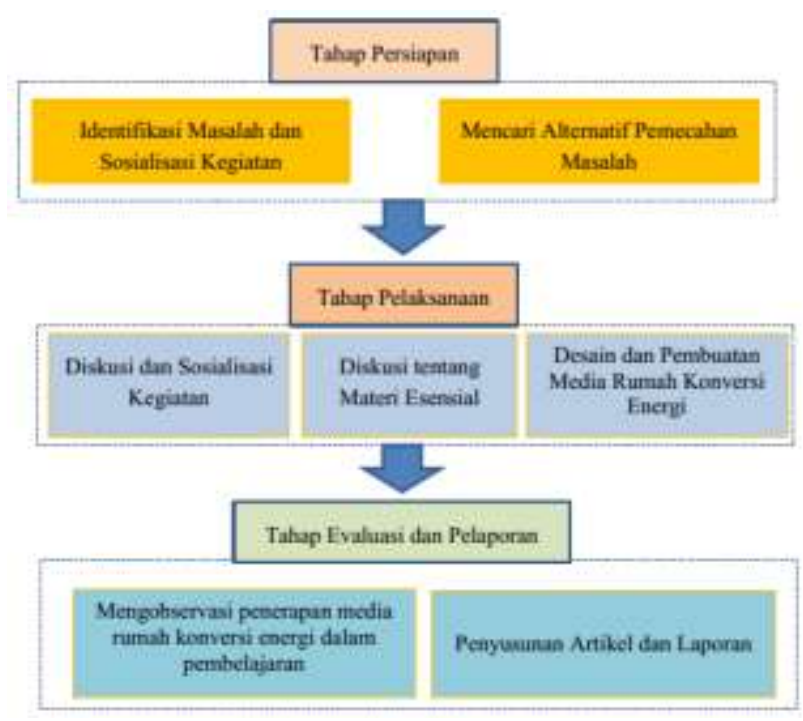

Gambar 1. Kerangka Pelaksanaan Kegiatan Pengabdian

Pada tahap persiapan dilakukan observasi terhadap guru IPA (Fisika) SMPN 21 Mataram, untuk mengidentifikasi permasalahan yang dihadapi dalam proses pembelajaran. Hasil observasi ditemukan bahwa pembelajaran kurang menggunakan media, sehingga peserta didik kurang aktif dalam proses pembelajaran. Salah satu upaya untuk menyelesaikan masalah tersebut adalah dengan dilakukan pelatihan mendesain dan cara menggunakan media pembelajaran rumah konversi energi kepada guru IPA SMPN 21 Mataram, sehingga materi yang abstrak dapat divisualisasikan.

Tahap selanjutnya adalah proses pelaksanaan yang merupakan tindak lanjut untuk menyelesaikan permasalahan yang dialami guru IPA (Fisika) dan peserta didik dalam proses pembelajaran, yaitu dengan dilaksanakan pelatihan langsung mengenai cara merancang media, sehingga pembelajaran menjadi interaktif. Pada tahapan ini, guru dibimbing untuk mengkaji materi esensial dan menyesuaikan media pembelajaran yang tepat dan efektif untuk membantu peserta didik seperti pada materi kalor dan energi dengan menggunakan rumah konversi energi. Tahap terakhir yaitu evaluasi hasil pelatihan yang dilakukan secara langsung dengan menilai pelaksanaan pelatihan guna untuk memperbaiki kekurangan-kekurangan agar kegiatan pelatihan selanjutnya lebih sempurna.

\section{Hasil dan Pembahasan}

Kegiatan pelatihan pembuatan media pembelajaran rumah konversi energi dan penerapannya dengan model STEM bagi guru IPA (Fisika) telah dilaksanakan secara daring melalui zoom meeting. Pelatihan tersebut berlangsung selama delapan bulan dimulai dari tahap persiapan, pelaksanaan dan terakhir tahap evaluasi. Sasaran pelatihan tersebut adalah semua guru IPA (Fisika).

Pada tahap persiapan dilakukan observasi terhadap guru IPA SMPN 21 Mataram, guna untuk mengidentifikasi permasalahan yang dihadapi dalam proses pembelajaran. Hasil observasi ditemukan bahwa pembelajaran kurang menggunakan media, sehingga peserta didik kurang aktif dalam proses pembelajaran. Salah satu upaya untuk menyelesaikan masalah tersebut adalah dengan dilakukan pelatihan kepada guru IPA (Fisika), sehingga materi yang abstrak dapat divisualisasikan. Adapun pada pelatiahan tersebut membahas materi kalor dan energi dengan menggunakan media rumah konversi energi.

Tahap pelaksanaan dilaksanakan pada tanggal 27 Oktober 2020 secara daring melalui zoom meeting. Tahap ini terdiri dari tiga kegiatan yaitu penyampaian materi, penjelasan pembuatan alat dan tanya jawab. Tahap ini dihadiri oleh dua orang narasumber yaitu dosen Fisika FKIP Unram dan 19 orang peserta yang terdiri dari guru Fisika SMA, Guru IPA SMP, dan Mahasiswa magister pendidikan IPA. Adapun dua orang narasumber tersebut adalah Dra. Susilawati, M.Si., Ph.D. sebagai narasumber 1 dan Drs. Aris Doyan, M.Si., Ph.D sebagai narsumber 2. Dra. Susilawati, M.Si., $\mathrm{Ph} . \mathrm{D}$ menyampaikan materi tentang pembuatan alat 
Inverter dan percobaan Melde, sedangkan Drs. Aris Doyan, M.Si., Ph.D menyampaikan materi tentang pembuatan alat konversi energi. Alat inverter, percobaan Melde dan alat konversi energi ditunjukan pada Gambar 4.1, 4.2 dan 4.3.
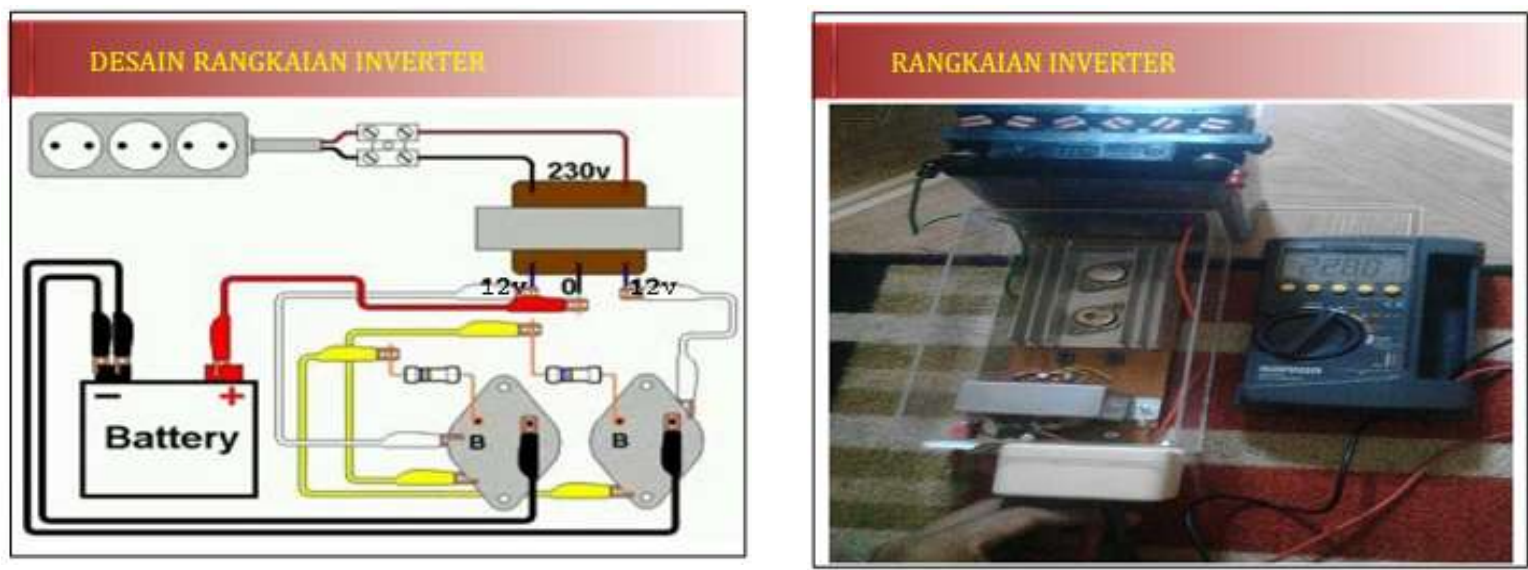

Gambar 1. Desain rangkaian Inverter
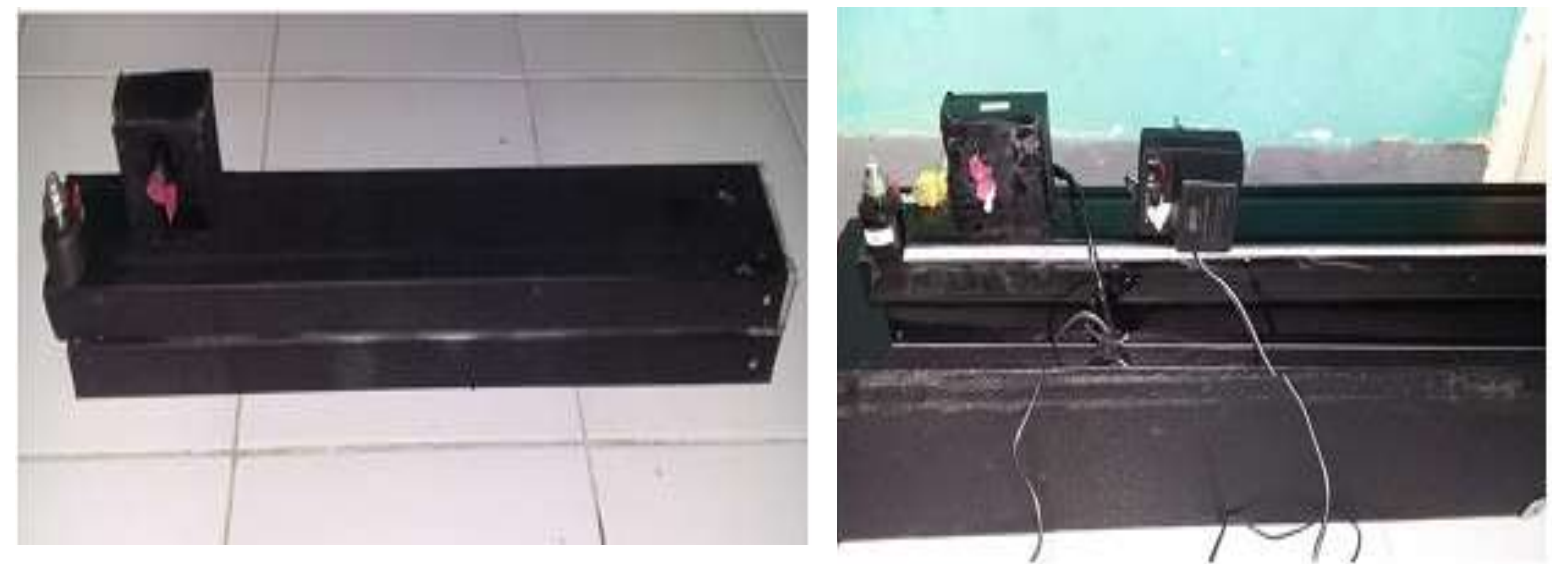

Gambar 4.1. Desain rangkaian untuk percobaan Mende
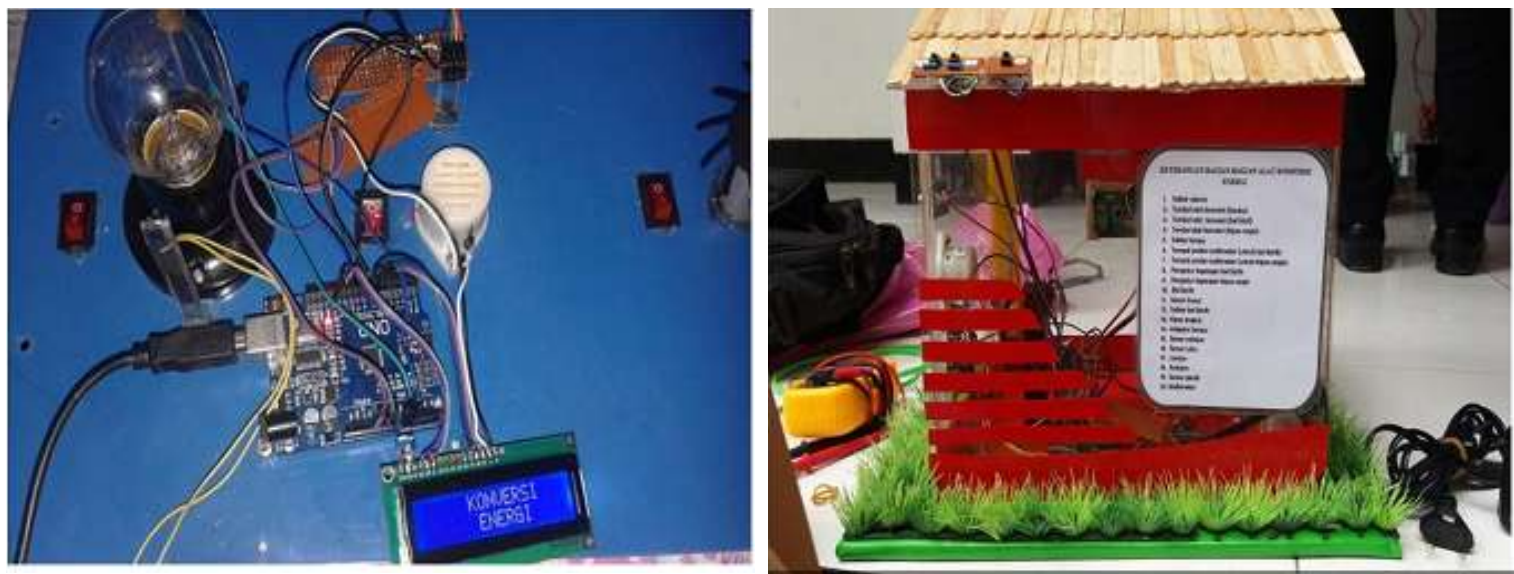

Gambar 4.3. Desain rangkaian konversi energi

Pada proses pembelajaran, terjadi banyak interaksi antara peserta pelatihan dengan narasumber yang ditandai dengan banyaknya peserta pelatihan melontarkan pertanyaan kepada narasumber terkait materi yang disampaikan. Hal ini menunjukan bahwa dalam kegiatan pembelajaran tersebut semua peserta pelatihan sangat antuasias dan aktif dalam mengikuti 
pembelajaran. Pada akhir pertemuan diberikan angket respon peserta terhadap diadakannya pelatiahan tersebut. Hasil respon peserta pelatihan dapat ditunjukan pada Tabel 4.1.

Table 4.1. Data respon peserta pelatihan

\begin{tabular}{|c|c|c|}
\hline$\overline{\mathrm{No}}$ & Nama & Pekerjaan \\
\hline$\overline{1}$ & Baiq Nunung H. & Mahasiswa S2 IPA \\
\hline 2 & Irmayani & Guru \\
\hline 3 & Erna Ajizah & Mahasiswa S2 IPA \\
\hline ( & Devi Ayu Septiani & Mahasiswa S2 IPA \\
\hline
\end{tabular}

5 Lalu Raftha P. Mahasiswa S2 IPA

6 Samsul Hadi Mahasiswa S2 IPA

7 Annisa Zikri R. Mahasiswa S2 IPA

8 Norma Juniati Mahasiswa S2 IPA

9 Yenni Desimarlina

10 Anak Agung Ayu Mahasiswa S2 IPA $\mathrm{T}$

11 Ayu Safitri Melit Mahasiswa S2 IPA

12 Kumala Ratna D. Guru

13 Wahyu Bintang I. Mahasiswa S2 IPA

14 Rabiatul Adawiyah

15 Husnul Fuad

16 Yenni D.

17 Siswadi

18 Ainun Jariah

19 Zulandri
Mahasiswa S2 IPA

Mahasiswa S2 IPA

Guru

Mahasiswa S2 IPA

Guru
Mahasiswa S2 IPA
Respon Peserta

Semoga berjalan dengan lancar, kegiatannya menarik sekali

Interaktif dan menarik. Semoga kedepannya ada zoom meeting seperti ini yang berkaitan dengan pengabdian dengan tema IPA lainnya.

Interaktif dan menarik

Kesan saya mengikuti kegiatan seminar yang dipesentasikan sangat menarik, dan menambah wawasan serta referensi saya nantinya untuk pengembangan alat praktikum.

Membuat lebih paham tentang komponen rangkaian inverter dan percobaan Melde untuk pengaplikasiannya di mata pelajaran Fisika sebagai pengganti alat yg rumit namun dengan fungsi yg sama.

Menarik

Sangat bermanfaat untuk mengembangkan kreativitas kita sebagai calon peserta didik, membuat alat-alat sederhana praktikum tanpa harus membeli yang mahal

Terimakasih banyak kepada pemateri yaitu Ibu Susi dan Bapak Aris mengenai materi yang telah disampaikan, ini sangat bagus dan menarik. Terimakasih telah memberikan materi yang sangat bermanfaat.

Alhamdulillah sangat bermanfaat, sangat menginspirasi untuk melakukan pengembangan media pembelajaran dalam penelitian nanti.

Sangat bermanfaat dan menginspirasi dalam pembelajaran IPA maupun fisika untuk mengembangkan alat praktikum yang dapat digunakan di sekolah.

Sangat memotivasi. Bahasa yang ringan, dan mudah di mengerti.

Terimakasih

Dapat memotivasi dan memberi inovasi mengenai pembuatan media pembelajaran

Banyak ilmu yang di dapatkan, di waktu yang akan datang semoga dapat di adakan lagi

Mendapatkan ilmu bagaimana menyusun media pembelajaran yang menarik dari hasil penelitian dan pengabdian tersebut.

Acaranya cukup menarik apalagi jika bisa langsung dipraktekkan oleh mahasiswa IPA

Alhamdulillah dapat tambahan ilmu dan cukup menarik

Sangat bermanfaat sekali bagi kami para guru terkait media-media pembelajaran (alat-alat) praktikum sebagai bantuan pembelajaran sehingga pembelajaran disekolah nantinya berhasil dan sukses.

Menambah pengetahuan dan wawasan mengenai pendampingan materi IPA

Sangat mengesankan.
Berdasarkan hasil respon peserta terhadap pelatihan bahwa secara keseluruhan kegiatan terlaksana dengan baik. Selain itu, peserta pelatihan merasa senang sudah memperoleh pengalaman yang sangat berharga dengan adanya kegiatan tersebut. Adapun pengalaman yang dimaksud yaitu: peserta yang terlibat dalam kegiatan pelatihan dapat merancang sebuah alat praktikum sederhana yang menarik tanpa harus membeli dengan harga yang mahal. Selain itu, peserta pelatihan cukup puas dengan diadakan pelatihan tersebut dan berkeinginan kegiatan pelatihan tersebut berkelanjutan.

\section{Kesimpulan}


Kegiatan pengabdian kepada masyarakat berupa pembuatan media pembelajaran rumah konversi energi dan penerapannya dengan model STEM bagi guru IPA (fisika) ini sangat bermanfaat bagi peserta karena dapat menambah wawasan tentang cara mendesain sebuah media pembelajaran sederhana dan menarik sehingga dapat meningkatkan keaktifan peserta didik saat pembelajaran. Secara umum kegiatan pelatihan ini berhasil dan tepat sasaran, karena peserta pelatihan merasa mendapatkan bekal cara mengembangan media pembelajaran dan termotivasi untuk menerapkannya saat pembelajaran. Selain itu, peserta pelatihan cukup puas dengan diadakan pelatihan tersebut dan berkeinginan kegiatan pelatihan tersebut berkelanjutan.

\section{Saran}

Kegiatan pelatihan pembuatan media pembelajaran rumah konversi energi dan penerapannya dengan model STEM bagi guru IPA (fisika) ini sudah berjalan dengan lancar. Kegiatan ini perlu dilanjutkan agar wawasan guru tentang media pembelajaran bertanbah sehingga tercipta pembelajaran aktif, efektif dan menyenangkan bagi peserta didik.

\section{Ucapan Terima Kasih}

Tim pengabdian mengucapkan terima kasih kepada kementerian riset, teknologi, dan pendidikan tinggi yang telah membiayai kegiatan pengabdian ini.

\section{Daftar Pustaka}

Adhelacahya, K., Nur, A.A., Said dan Habsari, R.A. Inovasi Pembelajaran Berbasis Science, Technology, Engineering and Mathematics (STEM) pada Anak Berkebutuhan Khusus Di Era Revolusi Industri 4.0. Jurnal Ilmiah Penalaran dan Penelitian Mahasiswa, (4), 1, 147-164.

Doyan, A, Susilawati, Bahri, S., Muhlis, dan Artayasa, I. P. (2019). Pelatihan Pemantapan Konsep Materi Fisika dan Pengukuran Bagi Guru IPA di SMPN 9 Mataram. Jurnal Pengabdian Magister Pendidikan IPA (JPMPI). (2), 1, 24-27.
Izzati, Nur. Linda Rosmery. Susanti. Nur Asma. (2019). Pengenalan Pendekatan STEM sebagai Inovasi Pembelajaran EraRevolusi Industri 4.0. I (2): 83- 89.

Stehle, S. M., \& Peters-Burton, E. E. (2019). Developing student 21 st Century skills in selected exemplary inclusive STEM high schools. International Journal of STEM Education, 6(1), 39. https://doi.org/10.1186/s40594-0190192-1.

Susilawati, Doyan, A., Taufik, M. dan Zuhdi, M. 2019. Pengayaan Materi Olimpiade Fisika dan Pelatihan Penyelesaian Soal-Soal Olimpiade Fisika Bagi Guru dan Siswa di SMP Islam Terpadu Putra Mataram. Jurnal Pengabdian Magister Pendidikan IPA (JPMPI), (2), 1, 34-36.

Torlakson.T.(2014).Innovate: A Blueprint for Science, Technology, Engineering, and Mathematics in California Public Education. California: State Superintendent of Public Instruction. 